\title{
COMPLETE AVULSION OF COMMON BILE DUCT WITH GRADE IV DUODENAL INJURY IN A CHILD FOLLOWING BLUNT INJURY ABDOMEN
}

Prashant M. Anadinni' ${ }^{1}$, Srinivas B. Kulkarni², Sanjeev Joshi³ ${ }^{3}$ Sandeep Y. Chinnapur ${ }^{4}$

\section{HOW TO CITE THIS ARTICLE:}

Prashant M. Anadinni, Srinivas B. Kulkarni, Sanjeev Joshi, Sandeep Y. Chinnapur. "Complete Avulsion of Common Bile Duct with Grade IV Duodenal Injury in A Child following Blunt Injury Abdomen". Journal of Evolution of Medical and Dental Sciences 2015; Vol. 4, Issue 70, August 31; Page: 12256-12258,

DOI: $10.14260 /$ jemds/2015/1767

ABSTRACT: Extrahepatic bile ducts injuries from blunt abdominal trauma are very rare. The criticality and the difficulty of these injuries are increased by the duodenal wall and the main pancreatic duct injuries. Case report demonstrates specific injury to common bile duct and duodenal wall without injury to pancreatic duct.

KEYWORDS: Common blie duct complete transaction, Duodenal injury, Blunt injury abdomen.

INTRODUCTION: Avulsion of the extrahepatic bile ducts from blunt abdominal trauma is an infrequently encountered condition.(1) The complexity of these injuries is increased by the degree of involvement of the duodenal wall and the main pancreatic duct. Mason, in an excellent review article in 1954, noted that there were "less than 100 cases which were recorded in the last century".(2) Hicken, in 1948 stated, "the traumatic rupture of the common bile duct occurs very infrequently and it is usually fatal".(3) Avulsion of CBD may be complete or partial. In any case the presentation depends upon the extent of biliary peritonitis and associated injuries.

CASE REPORT: A 5 years old male child presented to the emergency room with severe abdominal pain and abdominal distention following self-fall and sustained blunt injury upper part of abdomen while playing 4 hours past. On examination patient was in tachypnea (30 cycles/min), tachycardia (124 beats/min) and hypotension (Systolic 60mmof Hg). Abdomen distended, tender with guarding and rigidity. Sluggish bowel sounds heard. There were no evidence of external injury. Patient resuscitated with iv fluids, ionotropes, catheterization, Ryles tube. Emergency ultrasound of abdomen and pelvis suggestive of peritoneal free fluid collection of $350 \mathrm{ml}$ probably haemoperitoneum (Figure 1). Diagnostic needle aspiration under USG guidance confirmed the same. Pts $\mathrm{Hb}$ was 8gm/dl, other blood parameters including renal function test, liver function test, serum electrolytes were within normal limits. Patient posted for emergency exploratory laparotomy, intra operatively around $350 \mathrm{ml}$ of blood mixed with bile, complete transection of distal $3^{\text {rd }}$ of common bile duct and grade IV injury $2^{\text {nd }}$ part of duodenum noted. Distal end of CBD was not able to identify on table. Thorough wash given, primary closure of duodenum, Roux-en-y choledochojejunostomy with feeding jejunostomy done. Laparotomy closed with abdominal drain in situ. Post operatively patient recovery was uneventful and drain removal was done on $10^{\text {th }}$ day and discharged on $15^{\text {th }}$ day.

DISCUSSION: The exact pathophysiology of extrahepatic bile ducts (EBD) injury still remains unclear, but a combination of the following theories may be responsible for it. The exact nature of the force necessary to cause injury to the EBD is unknown although (a) impingement and compression of the ductal system on the vertebral column,(4),(5) (b) external compression of the gall bladder with transmitted rise in intraductal pressures resulting in blowout of the duct,(2) and (c) laceration of the 
ductal system at the junction of its fixed and mobile portions,(6,) may explain EBD injuries. Total transection of the duct can be repaired by primary endtoend anastomosis if the case is freshly diagnosed with no infection and the distal end of the duct is identified and healthy. Primary choledochoduodenostomy or RouxenY choledochojejunostomy(7) are other options if the distal end is not identified or there is fear of postoperative stricture. The literature revealed few previously reported cases of complete transection of the common duct at the junction with the duodenum which had been caused by blunt trauma. Lysaght performed a cholecystogastrostomy(8) and Mast and $\mathrm{Oz}$ performed a choledocoduodenostomy,(9) while Hinshaw, Turner and Carter performed a loop choledocojejunostomy and a jejunojejunostomy for this lesion.(3) Tolins located the distal severed common duct through duodenostomy with retrograde probing through the ampulla of Vater and thus was able to perform a direct duct to duct anastomosis.

\section{REFERENCES:}

1. Neely WA, Hardy JD. Traumatic severance of the common bile duct: an unusual case. Ann Surg 1961 Nov;154: 874-6.

2. Mason LB, Sidbury JB, Guiring S. Rupture of the extra-hepatic bile ducts due to a nonpenetrating trauma. Ann Surg 1954; 140: 234-1.

3. Hinshaw DB, Turner GB, Carter R. Transection of the common bile duct which was caused by a nonpenetrating trauma. Am J Surg 1962; 104

4. Lewis KM. Traumatic Rupture of the Bile Ducts. Ann Surg 1938 Aug; 108 (2): 237.

5. Mohardt JH. Traumatic rupture of the common bile duct; Report of a case and review of the literature. Q Bull Northwest Univ Med Sch 1956; 30(1): 16-20.

6. Fish JC, Johnson GL. Rupture of Duodenum following Blunt Trauma: Report of a Case with Avulsion of Papilla of Vater. Ann Surg 1965 Nov; 162(5): 917-9.

7. Lysaght AC. A case of traumatic severance of the common bile duct. Brit J Surg 1939; 26: 646.

8. Mast $\mathrm{WL}, \mathrm{Oz} \mathrm{M}$. Complete severance of the common bile duct due to external blunt trauma to the abdomen. J Internat Coll Surg 1960; 34: 726.

9. Tolins SH. Complete severance of the common bile duct secondary to blunt trauma. Ann Surg 1959; 149: 61.

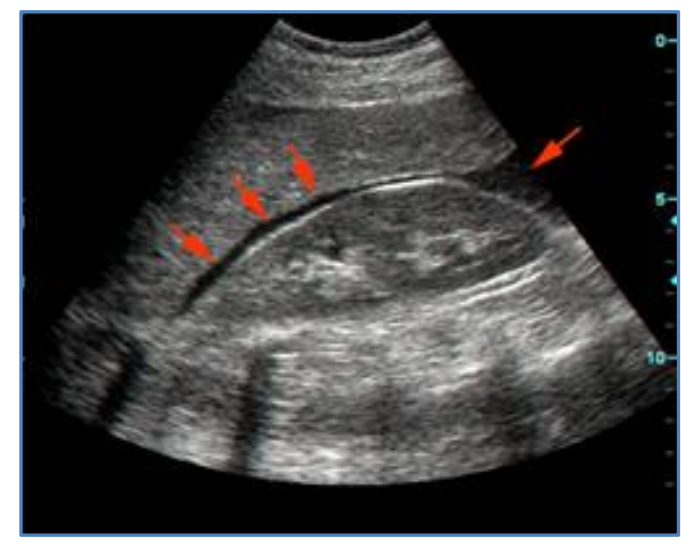

\section{Fig. 1}




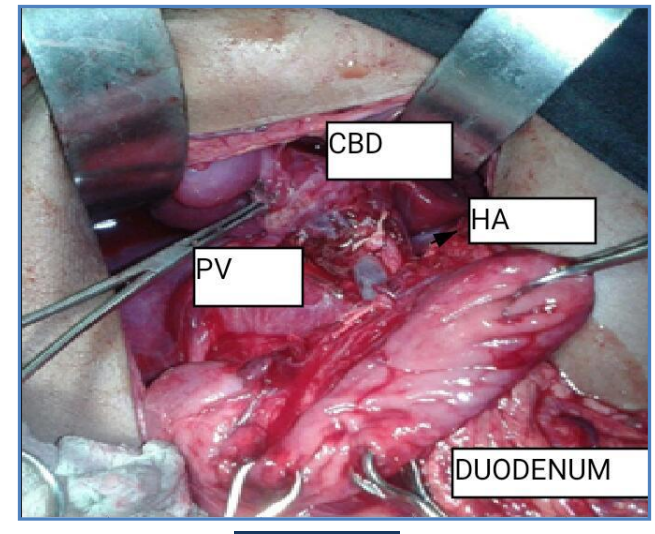

Fig. 2

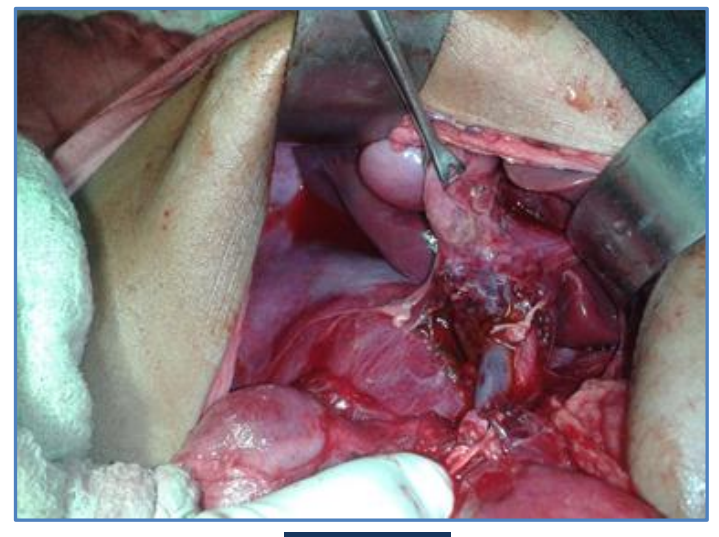

Fig. 3

\section{AUTHORS:}

1. Prashant M. Anadinni

2. Srinivas B. Kulkarni

3. Sanjeev Joshi

4. Sandeep Y. Chinnapur

\section{PARTICULARS OF CONTRIBUTORS:}

1. Assistant Professor, department of General Surgery, Raja Rajeswari Medical College and Hospital Bengaluru.

2. Assistant Professor, department of General Surgery, Raja Rajeswari Medical College and Hospital Bengaluru

3. Associate Professor, department of General Surgery, Raja Rajeswari Medical College and Hospital Bengaluru.

FINANCIAL OR OTHER

COMPETING INTERESTS: None
4. Assistant Professor, department of General Surgery, Raja Rajeswari Medical College and Hospital Bengaluru.

\section{NAME ADDRESS EMAIL ID OF THE CORRESPONDING AUTHOR:}

Dr. Prashant M. Anadinni, \# 50, S1, 2 ${ }^{\text {nd }}$ Cross, $1^{\text {st }}$ Main, Chamarajpet, Bengaluru-560018.

E-mail: doc.prashant73@gmail.com

Date of Submission: 14/08/2015.

Date of Peer Review: 17/08/2015.

Date of Acceptance: 27/08/2015.

Date of Publishing: 31/08/2015. 